\title{
Effects of hormone replacement therapy in rheumatoid arthritis: a double blind placebo-controlled study
}

\author{
A G MacDonald, E A Murphy, H A Capell, U Z Bankowska, S H Ralston
}

\begin{abstract}
Aims-To study the effects of ovarian hormone replacement therapy (HRT) on bone mineral density and disease activity in postmenopausal women with rheumatoid arthritis (RA).

Method-A placebo controlled doubleblind study was carried out on 62 patients with RA, 22 on placebo and 40 on HRT (transdermal oestradiol patches twice weekly for 48 weeks plus norithisterone tablets when clinically indicated). Bone mineral density of spine, hip and wrist was measured at 0 and 48 weeks and clinical and laboratory measures of general wellbeing and disease activity at $0,12,24$ and 48 weeks.
\end{abstract}

Results-Thirteen of $22(59 \%)$ of placebo and 31 of $40(78 \%)$ of the HRT group completed 48 weeks in the study. At entry, bone mineral density (BMD) values in the lumbar spine and femoral neck were similar to those in age and sex matched controls in both treatment groups, whereas at the distal radius, BMD was significantly reduced to approximately $50 \%$ of control values (both $p<0.001$ from controls). In the HRT group, spine BMD increased significantly by a median of $+0.94 \%$ at 48 weeks $(p=0.024)$, but did not change significantly in the placebo group. BMD at the femoral neck and distal radius did not change in either group. In the HRT group, there was significant improvement in well being as assessed by the Nottingham Health Care Profile $(p<0.01)$ and in the articular index $(p<0.05)$. There were no significant changes in ESR or CRP in either group.

Conclusion-Transdermal HRT was well tolerated, increased well being, reduced articular index and increased lumbar spine bone density over a one year period in postmenopausal women with RA. Although no laboratory evidence was found of a disease modifying effect, the symptomatic benefits and improvements in bone density indicate that HRT may be a valuable adjunct to conventional antirheumatic therapy in RA.

(Ann Rheum Dis 1994; 53: 54-57)

Generalised osteoporosis with associated fractures of the spine and hip are a recognised complication of rheumatoid arthritis (RA). ${ }^{12}$
While the causes of systemic osteoporosis in $\mathrm{RA}$ are unclear, contributing factors include corticosteroid use, immobilisation, postmenopausal status, and the bone resorbing effects of pro-inflammatory cytokines. ${ }^{3}$ Whatever the underlying cause, postmenopausal women with $\mathrm{RA}$ represent a group at increased risk of osteoporotic fracture and this may contribute to the morbidity already experienced by these individuals. ${ }^{12}$

The role of sex hormones in protecting against osteoporosis are well established ${ }^{4}{ }^{5}$ and it has been suggested that hormonal contraceptives and ovarian hormone replacement therapy (HRT), may protect against the development and progression of RA. ${ }^{6-8}$ In the light of this, postmenopausal women with RA constitute a group who might be expected to derive particular benefit from HRT. Although short term oestrogen therapy has been shown to be of benefit in suppressing some aspects of disease activity in $\mathrm{RA},{ }^{9}$ the long-term effects of HRT in this situation are poorly documented. The aim of this study was to evaluate the effects of HRT on regional bone mass, disease activity and general well being in postmenopausal women with RA.

\section{Patients and methods}

Consecutive postmenopausal and perimenopausal women attending outpatient clinics at the Centre for Rheumatic Disease, Glasgow, were invited to participate in the study and 62 were enrolled. All had definite or classic rheumatoid arthritis (American Rheumatism Association criteria), were in Steinbrocker functional class I and II, and had oestradiol and gonadotrophin levels consistent with a postmenopausal state. For ethical reasons, those with significant menopausal symptoms were excluded. Patients were randomised on a double blind basis to receive either placebo $(n=22)$ or hormone replacement therapy (HRT) $(n=40)$. The larger number of patients in the HRT wing of the study arose because of an interruption in the availability of placebo medication resulting in a $2: 1$ ratio of randomisation in favour of the active treatment. HRT consisted of oestradiol patches twice weekly ('Estraderm 50'; Ciba-Geigy), supplemented in $33 / 40(82 \%)$ of cases with oral norethisterone $1 \mathrm{mg}$ daily for 10 days on a cyclical basis. The placebo group received matching therapy. Patients were supervised by a gynaecologist (UB) who was aware of which treatment was being given; all other investigators 
and the patients were 'blind' to the identity of the therapy. Clinical measurements of disease activity, general well being and functional status included: Ritchie articular index, duration of morning stiffness, pain score (visual analogue scale; $0-10$ ) and general well being score (visual analogue scale 0-10). General health status was assessed by the Nottingham Health Profile questionnaire. ${ }^{10}$ Standard antirheumatic therapy including non-steroidal anti-inflammatory drugs and second line antirheumatic therapy were continued and doses adjusted according to standard clinical practice during the study. Biochemical and haematological variables were measured using standard laboratory techniques.

Bone mineral density (BMD) was measured at 0 and 48 weeks by dual photon absorptometry at the lumbar spine (mean of values in lumbar vertebrae 2-4) and in the femoral neck, using a Lunar DP3 dual photon absorptiometer. The long-term precision of this instrument for the lumbar spine measurements is $2.0 \%$ and $3.0 \%$ for the femoral neck. BMD at the distal $1 / 3$ of the radius was measured by single photon absorptometry using a Norland 287 osteodensitometer (long-term precision 3\%). BMD measurements were expressed in relation to locally-derived age and sex matched normals.

As some of the data were not normally distributed, non-parametric (Wilcoxon matched pairs signed rank test for paired samples and the Mann Whitney $U$ test) were used in statistical analysis.

\section{Results}

PRE-TREATMENT CHARACTERISTICS

Both groups were well matched at the outset of the study for the following variables (expressed as medians and range); age: placebo $=55(41-69) \quad v$ HRT $=53(41-64)$ years, age at menopause: placebo $=48(39-55)$ $v$ HRT $=48(30-53)$ years; duration of RA: placebo $=17(2-40) v$ HRT $=11(2-45)$ years. Of the placebo group, $63 \%$ were taking disease modifying drugs (salazopyrine $4(28 \%)$; gold 5 (35\%); penicillamine $3(21 \%)$, methotrexate 2 (14\%), compared with $65 \%$ of the HRT group (salazopyrine $10(30 \%)$; pencillamine $5(16 \%)$; gold $10(33 \%)$; hydroxychloroquine $3(10 \%)$ azathioprine $2(6 \%)$ ). One patient treated with HRT was on low dose prednisolone. BMD values in the spine and femoral neck did not differ significantly from those in locally-derived age and sex matched controls; Lumbar spine $\mathrm{BMD}($ placebo $)=92 \%(71-118) v(\mathrm{HRT})=$ 98\% (70-120); femoral neck BMD (placebo) $=96 \%(77-121) \vee 93 \%(59-126)$. BMD of the distal radius was, however, substantially reduced in both groups compared with controls; placebo $49 \%(36-73)$ v 55\% (25-71); both $\mathrm{p}<0.0001$ from controls).

COMPLIANCE AND TOLERABILITY

HRT therapy was well tolerated; 31 of the original $40(78 \%)$ patients randomised to HRT were still receiving treatment by one year in comparison with 13 of the $22(59 \%)$ of patients in the placebo group. Reasons for withdrawal were varied and included; menstrual bleeding (1 placebo, 2 HRT); depression (1 placebo); unable to attend for follow up (2 HRT); abnormal lipids (1 placebo); poor compliance (1 HRT); death due to intercurrent illness (1 placebo, $1 \mathrm{HRT}$ ); skin reaction to patches (1 HRT); poor symptomatic response (4 placebo). Data from patients who withdrew were not included in further analysis.

SYMPTOMS AND DISEASE ACTIVITY

Changes in clinical and laboratory indices of disease activity and in the Nottingham Health Profile assessment are summarised in the table. In the HRT group there was a statistically significant improvement in subjective overall well being as assessed by a visual analogue scale at week 12 and 48 (both $p<0.05$ from baseline) and in the Ritchie articular index by week 48 of the study ( $p<0.05$ from baseline). There were no changes in laboratory indices of

Effect of HRT and placebo on clinical and laboratory indices of disease activity and on general well being

\begin{tabular}{|c|c|c|c|c|c|c|c|c|}
\hline \multirow[t]{2}{*}{ Time (weeks) } & \multicolumn{4}{|l|}{ Placebo } & \multicolumn{4}{|l|}{$H R T$} \\
\hline & 0 & 12 & 24 & 48 & 0 & 12 & 24 & 48 \\
\hline $\begin{array}{l}\text { Clinical indices of disease act } \\
\text { Articular index } \\
\text { Pain score }(\mathrm{cm}) \ddagger \\
\text { Wellbeing score }(\mathrm{cm}) \S \\
\text { Morning stiffness (minutes) }\end{array}$ & $\begin{array}{l}\text { vity } \\
28 \\
6 \cdot 0 \\
5 \cdot 0 \\
30\end{array}$ & $\begin{array}{l}15 \\
6 \cdot 3 \\
5 \cdot 3 \\
45\end{array}$ & $\begin{array}{l}15 \\
5 \cdot 1 \\
5 \cdot 0 \\
30\end{array}$ & $\begin{array}{l}14 \\
7 \cdot 0 \\
5 \cdot 1 \\
30\end{array}$ & $\begin{array}{l}24 \\
5 \cdot 0 \\
5 \cdot 0 \\
60\end{array}$ & $\begin{array}{l}20 \\
5 \cdot 3 \\
6 \cdot 5^{\star} \\
60\end{array}$ & $\begin{array}{l}16 \\
6 \cdot 0 \\
6 \cdot 1 \\
60\end{array}$ & $\begin{array}{l}15^{\star} \\
5 \cdot 0 \\
7 \cdot 5 \dagger \\
60\end{array}$ \\
\hline $\begin{array}{l}\text { Laboratory indices of disease } \\
\text { Haemoglobin }(\mathrm{g} / \mathrm{l}) \\
\text { ESR (mm/hr) } \\
\text { C-reactive protein }(\mathrm{mg} / \mathrm{l})\end{array}$ & $\begin{array}{l}\text { activity } \\
120 \\
28 \\
12\end{array}$ & $\begin{array}{r}119 \\
23 \\
10\end{array}$ & $\begin{array}{r}124 \\
32 \\
10\end{array}$ & $\begin{array}{r}122 \\
32 \\
12\end{array}$ & $\begin{array}{r}122 \\
34 \\
19\end{array}$ & $\begin{array}{c}124 \\
38 \\
16.5\end{array}$ & $\begin{array}{c}121 \\
35 \\
17 \S\end{array}$ & $\begin{array}{l}122 \\
31 \\
17 \cdot 5\end{array}$ \\
\hline $\begin{array}{l}\text { Nottingham profile part I } \\
\text { Energy level } \\
\text { Pain perception } \\
\text { Emotional level } \\
\text { Sleep } \\
\text { Physical mobility }\end{array}$ & $\begin{array}{l}60 \cdot 8 \\
57 \cdot 8 \\
26 \cdot 2 \\
35 \\
41 \cdot 8\end{array}$ & $\begin{array}{l}62 \\
54 \cdot 4 \\
13 \cdot 4 \\
53 \cdot 5 \\
49 \cdot 2\end{array}$ & $\begin{array}{l}60 \cdot 8 \\
49 \cdot 4 \\
9 \cdot 8 \\
35 \\
42 \cdot 8\end{array}$ & $\begin{array}{l}63 \cdot 2 \\
49 \cdot 2 \\
19 \cdot 2 \\
50 \cdot 4 \\
44\end{array}$ & $\begin{array}{l}60 \cdot 8 \\
46 \cdot 5 \\
24 \cdot 8 \\
34 \cdot 3 \\
44\end{array}$ & $\begin{array}{l}24^{\star} \\
36 \cdot 5 \\
0^{\star} \\
12 \cdot 6 \\
41 \cdot 9\end{array}$ & $\begin{array}{l}24^{\star} \\
48 \cdot 9 \\
0^{\star} \\
28 \cdot 7 \\
41 \cdot 9\end{array}$ & $\begin{array}{l}25^{\star} \\
46 \cdot 5 \\
7 \cdot 2 \dagger \\
12 \cdot 6 \dagger \\
48\end{array}$ \\
\hline $\begin{array}{l}\text { Nottingham profile part II } \\
\text { Activities of daily living }\end{array}$ & 3 & $3 \cdot 5$ & 4 & 3 & 4 & 3 & 3.5 & $2 \cdot 5^{\star}$ \\
\hline
\end{tabular}


disease activity such as haemoglobin, platelet count, ESR or C-reactive protein in either the HRT or the placebo group, although the degree of inflammatory activity at baseline as judged by these variables was relatively low. The only significant between group differences were in well being (greater in the HRT group at week 48; $\mathrm{p}<0.05$ ) and C-reactive protein (higher in the HRT group at week $24 ; \mathrm{p}<0.05$ ).

The results of the Nottingham Health Profile assessment are shown in two parts. Part I assesses symptomatic well being with specific questions (pain, social isolation, mobility, emotional reaction and energy). Part II assesses the effect of these on the activities of daily living. Improvements are represented by lower values, deterioration by higher values. Significant improvements in energy levels and

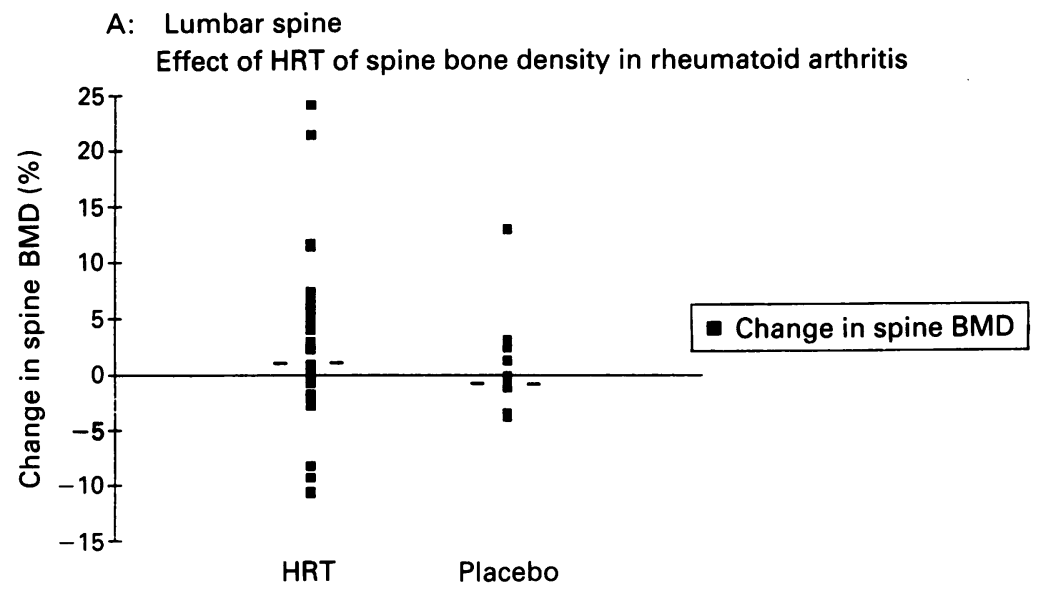

B: Femoral neck density

Effect of HRT on hip bone density in rheumatoid arthritis

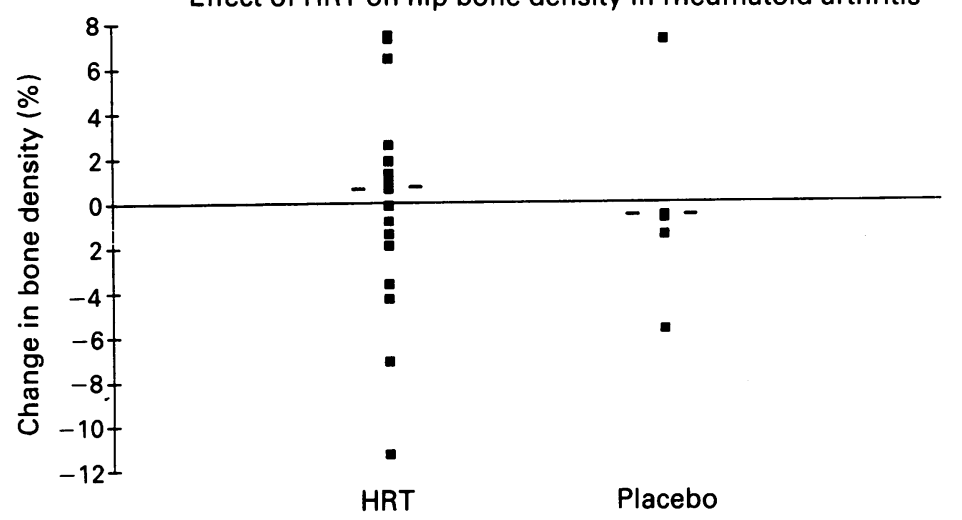

C: Distal radius

Effect of HRT on wrist bone density in rheumatoid arthritis

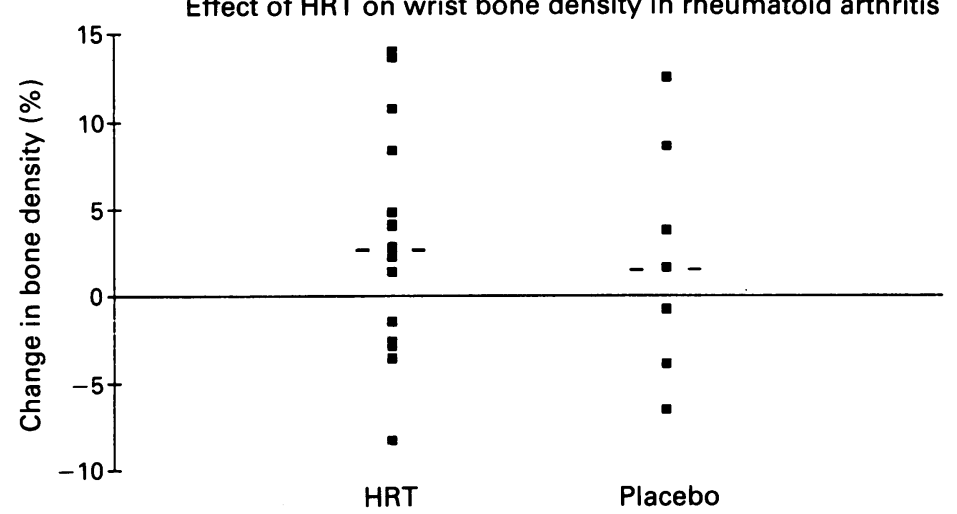

All BMD data are expressed as percentage change from baseline.

Effect of HRT and placebo on bone density. emotional state from week 12 onwards were noted in the HRT group and in sleep pattern at week 48 . There was no significant change in these variables in the placebo group. Neither group showed improvements in pain perception or physical mobility. In the HRT group the overall score fell-reflecting an improvement in activities of daily living - at week 48 $(p=0.0024)$.

\section{HORMONAL DATA}

Median serum oestradiol levels were low pretreatment and did not differ between the groups (HRT $60 \mathrm{pmol} / \mathrm{l}$; placebo $50 \mathrm{pmol} / \mathrm{l}$ ). In the HRT group, oestradiol increased significantly to a median of $120 \mathrm{pmol}$ at week 12 , $100 \mathrm{pmol}$ at week 24 and $110 \mathrm{pmol} / \mathrm{l}$ at week 48 (all $\mathrm{p}<0.01$ from baseline). Oestradiol levels did not change in the placebo group. Median LH and FSH levels were elevated to a similar degree in both groups before treatment: LH $44 \mathrm{u} / 1$ (HRT); $45 \mathrm{u} / 1$ (placebo); FSH $40 \mathrm{u} / 1$ (HRT); $40 \mathrm{u} / 1$ (placebo). LH fell significantly in the HRT group to 25 and $26 \mathrm{u} / \mathrm{l}$ at week 12 (both $\mathrm{p}<0.001$ ) and $36 \mathrm{u} / \mathrm{l}$ at week $48(\mathrm{p}<0.05)$. There was no significant change in $\mathrm{LH}$ in the placebo group or in FSH in either group.

\section{BONE DENSITY DATA}

These are shown in fig A-C. In the HRT group, lumbar spine BMD values increased significantly by a median of $+0.94 \%(p<0.03)$, whereas there was no significant change in the placebo group $(-0.50 \%, p=N S)$. Unfortunately, a combination of technical difficulties in positioning patients for hip scans, combined with a malfunction of our wrist densitometer during the study meant that there were relatively few paired BMD measurements available for the femoral neck and wrist particularly in the placebo group. Although there was a trend in favour of HRT there was no significant change in either femoral neck BMD or wrist BMD values between 0 and 48 weeks; femoral neck; $+0.69 \%$ (HRT) $v-0.65$ (placebo); wrist; $+2 \cdot 72 \%$ (HRT) $v+1 \cdot 60 \%$ (placebo).

\section{Discussion}

Hormone replacement therapy offers several potential benefits for postmenopausal women with rheumatoid arthritis. Apart from the well documented protective effect of HRT on postmenopausal bone loss and osteoporotic fracture, ${ }^{45}$ there is evidence to suggest that sex hormones may protect against the development of RA, or modulate disease activity. ${ }^{6-8}$ The therapeutic effects of sex hormones in RA have been little studied although a recent short term crossover trial of unopposed oestrogen suggested that this hormone may suppress some aspects of disease activity. ${ }^{9}$ In this study, we investigated the longer term effects of conventional HRT on disease activity and bone density in RA. We found that over a one year period, transdermal HRT resulted in a significant increase in median bone density of 
the lumbar spine of approximately $+1 \%$ compared with a slight decrease $(-0.5 \%)$ in placebo-treated patients. These data are qualitatively similar to those recently reported by Stevenson $e a^{11}$ who found a $2.5 \%$ increase in mean spinal BMD after 18 months of treatment with the same dose of transdermal oestrogen in normal postmenopausal women. The loss of bone in placebo treated patients was greater in their study, however, $(-2 \%)$ possibly due to the fact that their patients were studied within two to three years of the menopause compared with five to seven years in this study. Like Stevenson et $a l^{11}$ and Sambrook et $a l,{ }^{12}$ who also studied the effects of sex hormones on bone density in RA, we found the protective effect of HRT on femoral neck density much less marked than in the lumbar spine. A recent study by van der Brink et $a l,{ }^{13}$ however, showed improvements in BMD at both sites. There are several potential explanations for these differences. Perhaps the most likely is that the femoral neck measurements largely reflect changes in cortical bone which remodels at a much slower rate than the trabecular bone of the vertebral bodies and hence may require longer periods of treatment to show changes, particularly in the light of the poorer precision of BMD measurements at the femoral neck. It has also been suggested that higher doses of oestrogen may be needed to prevent femoral bone loss in some cases. ${ }^{11}$

The plasma oestradiol concentrations achieved in the present study (100-120 pmol/ 1) have previously been shown-on the basis of biochemical measurements-to be effective in suppressing bone turnover in normal postmenopausal women. ${ }^{14}$ Some patients treated with HRT continued to lose bone despite this, however, (figure A-C) indicating that therapy may need to be tailored on an individual level on the basis of bone density measurements. Although the risk of osteoporotic fractures affecting both the hip and spine is increased by a factor of between $1 \cdot 5-2 \cdot 0$ times in RA patients $^{12}$ data has been presented to suggest that the pattern of bone loss in early RA is periarticular, rather than systemic in distribution. ${ }^{3}$ Our observations are consistent with this, as we found a marked reduction in bone density of the distal radius in RA patients, with BMD values in the spine and hip which were similar to those in an age and sex matched control population. While these data argue against a specific systemic osteoporosis in RA per se, it is probable that multiple factors such as steroid use, relative immobility, smoking and postmenopausal status may combine to increase the risk of bone loss and fracture in RA. ${ }^{12}$

The second aim of our study was to assess the tolerability of HRT in RA and study its effects on general well being and disease activity. An important finding was the excellent tolerability of HRT; only one patient on HRT withdrew from the study due to difficulties with resumption of menstrual bleeding and overall, $78 \%$ of the HRT group were still on therapy at two years compared with $59 \%$ in the placebo group. The high rate of compliance may have related to the symptomatic benefits which occurred in the HRT group. Particularly striking were the improvements in energy level, emotional level, and sleep patterns as assessed by the Nottingham Health Profile and the general well being score and articular index. We were, however, unable to demonstrate any specific antirheumatic effect as reflected by changes in ESR or C-reactive protein levels. Most of the patients studied were also taking disease modifying drugs, however, and as a result, had relatively low levels of ESR and CRP; it would be interesting to repeat the study in a group of patients with more evidence of inflammatory activity. The higher CRP level in the HRT group at week 24 is of doubtful significance and was probably related to random variation about the mean of the generally higher CRP levels observed in the HRT group.

In summary, we have found that HRT therapy in postmenopausal women with RA increased bone density in the lumbar spine, resulted in a significant improvement in general well being, but-in this group of patients at least-did not alter laboratory indices of disease activity. These symptomatic benefits, coupled with the protective effect on spinal bone density, however, indicate that HRT may be a useful adjunct to conventional therapy in the management of RA.

We thank Ciba-Geigy for providing the medication used in the study, Professor Roger Sturrock for permission to study his patients, Mrs Sylvia Armstrong for performing metrology measurements, Dr Ian Boyle and Dr David McKay Hart fo access to their bone densitometers, Mrs Dorothy McKnight for assistance with the statistical analysis and Miss Ann Tierney for typing the manuscript. This study was partly supported by a Senior Clinical Research Fellowship award to SHR from the Wellcome Trust.

1 Hooyeman J R, Melton L J, Nelson A M, O'Fallon M W, Riggs B L. Fractures after rheumatoid arthritis. A population based study. Arthritis Rheum 1984; 27: 1353-61.

2 Spector T D, Hall G M, McCloskey E V, Kanis J A. Risk of vertebral fracture in women with rheumatoid arthritis. $B M 7$ 1993; 306: 558 .

3 Sambrook P N, Reeve J. Bone disease in rheumatoid arthritis. Clinical Science 1988; 74: 225-30.

4 Lindsay R, Hart D M, Forrest C, Baird C. Prevention of spinal osteoporosis in oophorectomised women. Lancet 1980; ii: $1151-4$

5 Weiss N S, Ure C L, Ballard J H, Williams A $R$, Daling J R. Decreased risk of fractures of the hip and lower forearm with post-menopausal use of oestrogen, NEngl F Med 1980; 303: 1195-8.

6 Hazes J M W, Dijkmans B A C, Vandenbroucke J P, De Vries R R P, Cats A. Pregnancy and the risk of developing rheumatoid arthritis. Arth Rheum 1990; 33 (12): 1770-5.

7 Vandenbroucke J P, Walkenburg H A, Boersma J W, et al. Oral contraceptives and rheumatoid arthritis: further evidence for a preventative effect. The Lancet 1983; ii: 839-42.

8 Hernandez-Avila $\mathrm{M}$, Liang $\mathrm{M} \mathrm{H}$, Willett W $\mathrm{C}$, et al. Exogenous sex hormones and the risk of rheumatoid arthritis. Arth Rheum 1990; 33 (7): 947-53.

9 Bijlsma J W J, Huber-Bruning O, Thijssen J H H. Effect of oestrogen treatment on clinical and laboratory manifestations of rheumatoid arthritis. Ann Rheum Dis 1987; 46: 777-9.

10 Hunt S M, McKenna S P, McEwen J, Williams J, Papp E. The Nottingham Health Profile: Subjective Health Status and Medical Consultations. Soc Sci Med 1981; 15A: $221-9$

11 Stevenson J C, Cust M P, Gangar K F, Hillard T C, Lees $B$, Whitehead $M$. Effects of transdermal versus oral hormone replacement therapy on bone density in spine and proximal femur in postmenopausal women. Lancet 1990; 336: 265-9.

12 Sambrook P, Birmingham J, Champion D, et al. Postmenopausal bone loss in rheumatoid arthritis: Effect of estrogens and androgens. F Rheumatol 1992; 19: 357-61.

13 van der Brink, H R, Lems W F, van Everdringen, A A, Bijlsma J W J. Adjuvant oestrogen treatment increases bone density in post-menopausal women with rheumatoid arthritis. Ann Rheum Dis 1993;52: 302-5.

14 Selby P, Peacock M. Dose dependent response of in post-menopausal women. BMF 1986; 293: 1337-9. 